\title{
Disruption of Glutamate Receptor-Interacting Protein in Nucleus Accumbens Enhances Vulnerability to Cocaine Relapse
}

\author{
Lisa A Briand ${ }^{*,}$, Blake A Kimmey', Pavel I Ortinski', Richard L Huganir ${ }^{2,3}$ and R Christopher Pierce' \\ 'Center for Neurobiology and Behavior, Department of Psychiatry, Perelman School of Medicine at the University of Pennsylvania, \\ Philadelphia, PA, USA; ${ }^{2}$ Howard Hughes Medical Institute, Baltimore, MD, USA; ${ }^{3}$ Department of Neuroscience, The Johns Hopkins University \\ School of Medicine, Baltimore, MD, USA
}

\begin{abstract}
Trafficking and stabilization of AMPA receptors at synapses in response to cocaine exposure is thought to be critical for expression of cocaine addiction and relapse. Glutamate receptor-interacting protein (GRIP) is a neuronal scaffolding protein that stabilizes GluA2 AMPARs at synapses but its role in cocaine addiction has not been examined. The current study demonstrates that conditional deletion of GRIP within the nucleus accumbens potentiates cue-induced reinstatement of cocaine seeking without affecting operant learning, locomotor activity, or reinstatement of natural reward seeking. This is the first study to demonstrate a role for accumbal GRIP in behavior. Electrophysiological recordings revealed increased rectification of AMPAR-mediated currents in the nucleus accumbens and increased AMPAR sensitivity to the GluA2-lacking AMPAR antagonist, I-naphthylacetyl spermine, indicative of an increased contribution of GluA2lacking calcium-permeable AMPARs. In addition, accumbal GRIP deletion was associated with blunted long-term depression, similar to what is seen following cocaine self-administration. Taken together, these results indicate that GRIP may modulate addictive phenotypes through its regulation of synaptic AMPARs by controlling their subunit composition and susceptibility to LTD. These effects are associated with changes in vulnerability to cocaine relapse and highlight GRIP as a novel target for the development of cocaine addiction therapeutics. Neuropsychopharmacology (2014) 39, 759-769; doi:I0.1038/npp.20 13.265; published online 13 November 20 I3
\end{abstract}

Keywords: cocaine; self-administration; GRIP; AMPA; LTD; synaptic plasticity

\section{INTRODUCTION}

Cocaine dependence is marked by high rates of relapse that poses a limitation on treatment of addicts (Alleweireldt et al, 2001; Ciccocioppo et al, 2001; McFall et al, 1992; Ouimette et al, 2007; Volkow et al, 2006). This vulnerability to relapse is in part mediated by the enduring changes in the salience of previously neutral stimuli that are associated with drug use (Robinson and Berridge, 2008). Cues previously paired with drug use elicit craving in human addicts and reinstate extinguished cocaine-seeking behavior in rodent models. Experience-dependent plasticity at glutamatergic projections to the nucleus accumbens has an important role in this form of maladaptive learning (Hyman et al, 2006; Wolf, 2002). Increases in GluA1, GluA2, and GluA2/3 AMPA receptor subunits have been demonstrated after days to weeks of forced abstinence following cocaine self-administration ( $\mathrm{Lu}$ et al, 2003; Tang et al,

*Correspondence: Dr LA Briand, Center for Neurobiology and Behavior, Department of Psychiatry, Perelman School of Medicine, University of Pennsylvania, TRL, 125 South 3 I st Street, Philadelphia, PA 19105, USA, Tel: +215573 5202, Fax: +215 5737605 ,

E-mail: Ibriand@mail.med.upenn.edu

Received 28 August 2013; revised 19 September 2013; accepted 26 September 2013; accepted article preview online 15 October 2013
2004), and corresponding increases have been seen in AMPA-mediated excitatory postsynaptic currents (EPSCs) (Ortinski et al, 2012).

Cocaine-induced changes in excitatory synaptic strength critically depend on trafficking of AMPA receptors to and from the synapse (Anderson et al, 2008; Boudreau et al, 2007). The majority of AMPARs within the nucleus accumbens of naive adult rodents are calcium-impermeable receptors (CI-AMPARs) that contain GluA2 subunits (Boudreau et al, 2007; Conrad et al, 2008; Reimers et al, 2011). Increases in excitatory efficacy following extended access to cocaine may involve synaptic incorporation of high-conductance, GluA2-lacking, and calcium-permeable receptors (CP-AMPARs) (Conrad et al, 2008; McCutcheon et al, 2011a; McCutcheon et al, 2011b). CP-AMPARs expression is not changed following short access selfadministration procedures (Purgianto et al, 2013), although increases in AMPAR-mediated currents have been reported following withdrawal from short access self-administration and following experimenter-administered cocaine (Kourrich et al, 2007; Mameli et al, 2009; Ortinski et al, 2012). In addition, there is evidence that disruption of AMPA receptor trafficking attenuates cocaine-primed reinstatement following short access self-administration (Famous et al, 2008). However, the trafficking proteins 
involved in these cocaine-induced alterations in AMPAR transmission are not clear.

Glutamate receptor-interacting protein (GRIP) is a PSD95/SAP90/DLG/ZO-1 (PDZ) domain-containing protein that interacts with the intracellular $\mathrm{C}$ terminus of GluA2/3 subunits and governs their trafficking in and out of the cell membrane (Dong et al, 1997). GRIP has been shown to be involved in long-term synaptic plasticity in the retina, hippocampus, and cerebellum (Summa et al, 2011; Takamiya et al, 2008; Xue et al, 2010), and alterations in GRIP phosphorylation, leading to changes in AMPAR transmission, occur following prenatal cocaine exposure (Bakshi et al, $2009 b$ ). Although very little research has been done examining the role of GRIP in specific behaviors, there is evidence that it may have a role in social interaction and sociability (Mejias et al, 2011). However, nothing is known about the role of GRIP in cocaine addiction and relapse. In this paper, we find that selective reduction of GRIP expression in the nucleus accumbens increases cue-induced reinstatement of cocaine, but not food seeking, and examine the synaptic and accumbal microcircuit signatures of this phenotype.

\section{MATERIALS AND METHODS}

\section{Subjects}

Mice homozygous for the Cre/lox-conditional allele of GRIP1 (flox/flox) and GRIP2 knockout $(-/-)$ were bred on a C57bl/6 background. Male mice (2-6-months old, 20$40 \mathrm{~g}$; age matched across group) are housed individually following stereotaxic surgery and during experimental paradigms. All animals were housed in a temperatureand humidity-controlled animal care facility with a 12-h light/dark cycle (lights on a 0700 hours). All procedures were approved by the University of Pennsylvania Animal Care and Use Committee. Cocaine was obtained from the National Institutes of Drug Abuse Drug Supply Program (Bethesda, MD) and dissolved in sterile $0.9 \%$ saline.

\section{Adeno-Associated Virus Constructs}

The adeno-associated virus (AAV) expressing Cre recombinase (AAV2/9.CMV.PI.CRE, titer $\left.2.84 \times 10^{13} \mathrm{gc} / \mu \mathrm{l}\right)$ and the AAV expressing green fluorescent protein (eGFP) (AAV2/ 9.CMV.eGFP, titer $3.74 \times 10^{13} \mathrm{gc} / \mu \mathrm{l}$ ) were generated by the University of Pennsylvania Vector Core. AAVs were diluted in sterile phosphate-buffered saline for microinjections.

\section{Intraaccumbal Microinjections}

GRIP1flox/flox mice (6-8 weeks) are anesthetized with isoflurane, and $\mathrm{AAV}\left(0.5 \mu \mathrm{l}, 1 \times 10^{9} \mathrm{GC} / \mu \mathrm{l}\right)$ is injected into the accumbens through a 30-gauge needle at a rate of $0.1 \mu \mathrm{l} /$ min. Stereotaxic coordinates for the nucleus accumbens are (from Bregma) anterior-posterior 1.5, lateral $+I-1.0$, dorso-ventral -5.0 . Following recovery, mice remain in the home cage for 8 weeks before behavioral testing.

\section{Operant Food Training}

Before catheterization, mice were trained to perform an operant response for sucrose pellets. The mice were placed in operant chambers (Med-Associates) and trained to spin a wheel manipulandum to receive a sucrose pellet. A compound cue stimulus consisting of a cue light above the active lever, a $2900-\mathrm{Hz}$ tone, and house light off was concurrent with each pellet administration, followed by an additional $8 \mathrm{~s}$ time-out when responding had no programmed consequences and the house light remained off. Mice were allowed to self-administer a maximum of 50 pellets per $60 \mathrm{~min}$ operant session. During the food training phase, mice were food restricted to $\sim 90 \%$ of their free-feeding weight. Mice returned to ad libitum food access 3 days following the start of the cocaine or sucrose selfadministration phase.

\section{Jugular Catheterization Surgery}

Before surgery, mice were anesthetized with $80 \mathrm{mg} / \mathrm{kg}$ ketamine and $12 \mathrm{mg} / \mathrm{kg}$ xylazine. An indwelling silastic catheter was placed into the right jugular vein and sutured in place. The catheter was then threaded subcutaneously over the shoulder blade and was routed to a mesh backmount platform (Strategic Applications) that secured the placement. Catheters were flushed daily with $0.1 \mathrm{ml}$ of an antibiotic (Timentin, $0.93 \mathrm{mg} / \mathrm{ml}$ ) dissolved in heparinized saline. The catheters were sealed with plastic obturators when not in use.

\section{Cocaine Self-Administration}

After surgery, mice were allowed for 3-4 days to recover before beginning behavioral testing. Mice were tested for cocaine selfadministration behavior in 2-h sessions (6 days per week) in the same chamber used for sucrose pellet self-administration. During testing, responding on the wheel now delivered an intravenous cocaine injection $(0.5 \mathrm{mg} / \mathrm{kg} /$ infusion), paired with the compound cue, under the same schedule as the food training. Following 10 days of cocaine self-administration, cocaine-seeking behavior was extinguished by replacing the cocaine with $0.9 \%$ saline. During this time, the light and tone cues paired with cocaine delivery were not present. Daily 2-h extinction sessions continued until animals had met the extinction criterion of $<25 \%$ of their self-administration responding. Twenty-four hours following meeting the extinction criterion, animals underwent a cue-induced reinstatement session. During the cue-induced reinstatement session, the light and tone cues were presented non-contingently for $20 \mathrm{~s}$ every $2 \mathrm{~min}$ during the first $10 \mathrm{~min}$ of the session. After this time period, the cues were presented contingent with operant responding, just as was done during the cocaine self-administration phase. During the reinstatement session, animals received saline infusions following responses on the active wheel.

\section{Sucrose Self-Administration}

Separate groups of mice were trained to lever press for sucrose as described above, and then received an additional 10 days of 2-h sucrose self-administration session, followed by extinction (no pellet delivery) and cue-induced reinstatement as described above.

\section{Acute Locomotor Response}

Locomotor activity was analyzed in a 'home cage' activity monitoring system (Med-Associates). The testing cage, 
which was identical in dimensions to the home cage, was placed in a photobeam frame $(30 \times 24 \times 8 \mathrm{~cm})$ with two levels of sensors arranged in an 8-beam array strip. A small amount of fresh bedding was scattered on the cage floor. Animals were placed within the testing cage and given $30 \mathrm{~min}$ to habituate before giving them an acute injection of cocaine $(15 \mathrm{mg} / \mathrm{kg})$. Locomotor activity was recording for 60 min following the injection.

\section{Western Blot}

Whole-cell tissue from naive viral-injected animals was processed for western blot as described previously (Ortinski et al, 2013). For all samples, protein concentration was quantified using a Pierce BCA Protein Assay Kit (Thermo Scientific). Equal amounts of protein $(30 \mu \mathrm{g})$ were loaded and separated in 10\% Tris-glycine gels (Invitrogen) and transferred to nitrocellulose membranes using the i-Blot dry transfer system (Invitrogen). Membranes were blocked with Li-Cor blocking buffer. Membranes were incubated for $48 \mathrm{~h}$ at $4{ }^{\circ} \mathrm{C}$ with selective antibodies to: GRIP1 (1:1000; BD Transduction Laboratories) and GAPDH (1:2000; Cell Signaling). Membranes were then incubated with fluorescent secondary antibodies (1:5000; IR-dye 680 or IR-dye 800) before being imaged on an Odyssey fluorescent scanner (Li-cor Biosciences). To ensure equal loading, GAPDH expression was used as a loading control.

\section{Nucleus Accumbens Slices}

Naive (8-12 weeks following viral injection) and cocaineexperienced (following extinction) mice were decapitated following cervical dislocation. The brain was removed and coronal slices $(250 \mu \mathrm{m})$ containing the nucleus accumbens were cut with a Vibratome (VT1000S, Leica Microsystems) in an ice-cold artificial cerebrospinal fluid solution (ACSF), in which $\mathrm{NaCl}$ was replaced by an equiosmolar concentration of sucrose. ACSF consisted of $130 \mathrm{mM} \mathrm{NaCl}, 3 \mathrm{mM} \mathrm{KCl}$, $1.25 \mathrm{mM} \mathrm{NaH}_{2} \mathrm{PO}_{4}, 26 \mathrm{mM} \mathrm{NaHCO}, 10 \mathrm{mM}$ glucose, $1 \mathrm{mM}$ $\mathrm{MgCl}_{2}$, and $2 \mathrm{mM} \mathrm{CaCl}_{2}$ ( $\mathrm{pH} 7.2-7.4$ when saturated with $95 \% \mathrm{O}_{2} / 5 \% \mathrm{CO}_{2}$ ). Slices were incubated in ACSF at $32-34{ }^{\circ} \mathrm{C}$ for $25 \mathrm{~min}$ and were kept at $22-25{ }^{\circ} \mathrm{C}$ thereafter, until transfer to the recording chamber. The osmolarity of all solutions was 305-315 mOsm. Slices were viewed using infrared differential interference contrast optics under an upright microscope (Eclipse FN1, Nikon Instruments) with a $\times 40$ water-immersion objective.

\section{Electrophysiology}

The recording chamber was continuously perfused (1-2 ml/ min) with oxygenated ACSF heated to $32 \pm 1{ }^{\circ} \mathrm{C}$ using an automatic temperature controller (Warner Instruments). Picrotoxin $(100 \mu \mathrm{M})$ was added to all solutions to block the $\mathrm{GABA}_{\mathrm{A}}$ receptor-mediated currents. Recording pipettes were pulled from borosilicate glass capillaries (World Precision Instruments) to a resistance of 4-7 $\mathrm{M}^{\circ}$ when filled with the intracellular solution (whole-cell recordings) or to a resistance of $1-2 \mathrm{M}^{\circ}$ when filled with extracellular solution (field recordings). All recordings were conducted with a MultiClamp700B amplifier (Molecular Devices).

\section{Long-Term Depression}

A bipolar tungsten stimulating electrode was placed within $100-300 \mu \mathrm{m}$ from the recording electrode and used to stimulate excitatory afferents at $0.1 \mathrm{~Hz}$. The field recordings were performed in areas of high fluorescence. The amplitude of current pulses was set at the intensity required to evoke a $70 \%$ maximal response. After $10 \mathrm{~min}$ of stable responding, LTD was induced using a paired-pulse protocol (50 ms inter-pulse interval) consisting of a $1-\mathrm{Hz}$ train of paired stimuli for $7.5 \mathrm{~min}$. The magnitude of LTD was estimated from fEPSPs recorded at $0.1 \mathrm{~Hz}$ for $50 \mathrm{~min}$ following the pairing protocol and comparing with the baseline fEPSP amplitudes.

\section{Whole-Cell Patch Recordings}

Intracellular solution contained (in $\mathrm{mM}$ ) the following reagents: $100 \mathrm{CsCH}_{3} \mathrm{O}_{3} \mathrm{~S}, 50 \mathrm{CsCl}, 3 \mathrm{KCl}, 0.2$ BAPTA, 10 HEPES, $1 \mathrm{MgCl}_{2}$, 2.5 phosphocreatine-2Na, 2Mg-ATP, 0.25 GTP-Tris, 1 QX-314 ( $\mathrm{pH} 7.2-7.3$ with $\mathrm{CsOH}$, osmolarity 280-290 mOsm). For mEPSC experiments, tetrodotoxin $(1 \mu \mathrm{M})$ was present in the bath. For rectification experiments, dl-AP5 $(50 \mu \mathrm{M})$ was present in the bath and spermine $(100 \mu \mathrm{M})$ was added to the intracellular solution. MSNs in the nucleus accumbens shell were identified by their morphology and the low-resting membrane potential $(-70$ to $-85 \mathrm{mV})$. All mEPSC recordings were conducted in whole-cell voltage-clamp mode $\left(V_{\mathrm{h}}=-70 \mathrm{mV}\right)$. Currents were low-pass filtered at $2 \mathrm{kHz}$ and digitized at $20 \mathrm{kHz}$ using a Digidata $1440 \mathrm{~A}$ acquisition board and pClamp 10 software (both from Molecular Devices). Access resistance (10$30 \mathrm{M}^{\circ}$ ) was monitored throughout the recordings by injection of $10 \mathrm{mV}$ hyperpolarizing pulses, and data were discarded if access resistance changed by $>25 \%$ over the course of data acquisition. mEPSCs were detected using an automated sliding-template-based algorithm in pClamp 10. This method compares the shape of the detected current to that of a template and has been shown to detect events with amplitude of at least three times the square deviation of the noise (Clements and Bekkers, 1997). All detected events were verified by visual confirmation of a fast rise time and slower exponential decay to baseline. For AMPAR-mEPSCs, the time constant of decay was based on a monoexponential fit to the decay phase of an average mEPSCs trace computed from a minimum of 50 individual mEPSCs. Mean mEPSC amplitude was analyzed from an average mEPSCs trace computed from a minimum of 50 individual mEPSCs. Mean mEPSC frequencies were analyzed from 20-s long trace segments. Evoked responses were triggered by $100 \mu \mathrm{s}$ constant-current pulses generated by an A310 Accupulser (World Precision Instruments) and delivered at $0.1 \mathrm{~Hz}$ via a bipolar tungsten stimulation electrode positioned within $100 \mu \mathrm{m}$ of the recorded cell. The amplitude of the current pulses was controlled by a stimulus isolator (ISO-Flex, AMPI) and was adjusted to elicit monosynaptic responses in the range of $100-300 \mathrm{pA}$ (the required stimulus intensity ranged from 15 to $80 \mu \mathrm{A}$ ). Rectification index was calculated as a ratio of the slope of a linear fit of $\mathrm{I}-\mathrm{V}$ points between -70 and $0 \mathrm{mV}$ to the slope of a linear fit of $\mathrm{I}-\mathrm{V}$ points between 0 to $+40 \mathrm{mV}$. Accordingly, an index of 1 represents perfect linearity, whereas values $>1$ indicate 

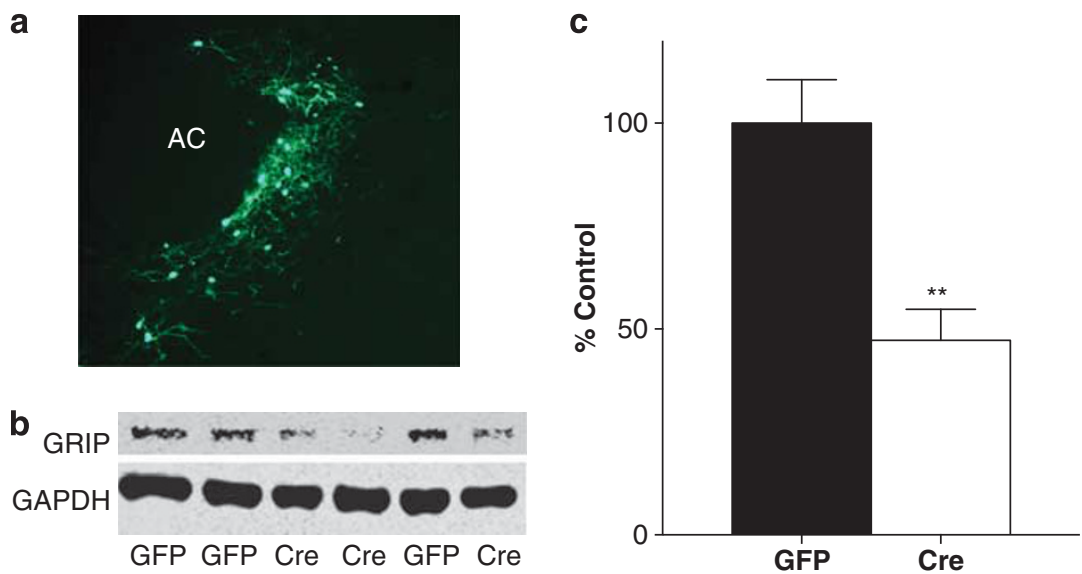

Figure I Cre recombinase injection into the Nucleus accumbens leads to a significant decrease in glutamate receptor-interacting protein (GRIP) protein. (a) Coronal mouse brain section showing viral expression of adeno-associated virus (AAV)-Cre tagged with eGFP throughout both the core and the shell subregions of the nucleus accumbens. (b) Representative western blot showing GRIP knockdown in nucleus accumbens following injection with AAV-Cre. (c) Quantification of western blot showing a significant decrease in GRIP protein in the nucleus accumbens following AAV-Cre injection, as normalized to glyceraldehyde 3-phosphate dehydrogenase (GAPDH). AAV-Cre GRIP KO $(N=15)$ : $47.3 \pm 7.5 \%$ of GFP control $(100 \pm 10.6 \%, N=19)$; $\mathrm{t}(32)=3.86$, *** $p=0.0005$.

inward rectification. For all measures, cells from at least three animals, within each group, were used. Recordings were taken from GFP + cells within both the accumbens core and shell.

\section{Data Analysis}

Data are presented as mean \pm SEM. Significance was determined using two-tailed Student's $t$-tests or two-way ANOVAs with a significance level of $p<0.05$.

\section{RESULTS}

\section{Viral Mediated Deletion of GRIP in the Nucleus Accumbens}

As previous work has shown that it is necessary to knock out both GRIP isoforms (GRIP1 and GRIP2) to observe a functional effect on cerebellar LTD, we used GRIP1-floxed mice on a GRIP2-null background (Takamiya et al, 2008). To directly examine the role of GRIP in cocaine reinforcement and reinstatement, mice were injected with AAV coexpressing Cre recombinase and GFP or GFP alone directly into the nucleus accumbens. This led to a significant decrease in GRIP expression within the nucleus accumbens 8 weeks following viral injection $(t(32)=3.86, p=0.0005$; Figure 1).

\section{Selective Deletion of GRIP in the Nucleus Accumbens Potentiates Cue-Induced Reinstatement}

Eight weeks after viral injections, GFP-injected controls $(n=18)$ and GRIP KO $(n=12)$ mice underwent 10 days of training to acquire operant responses for food. GRIP deletion within the nucleus accumbens did not alter the ability of mice to acquire an operant response nor did it affect number of rewards received (Figure $2 a$ and $b$ ). Following this training, mice received jugular catheterization surgery and underwent 10 days of cocaine self- administration. Accumbal GRIP deletion did not alter the reinforcing efficacy of cocaine as indicated by equal responses for a fixed dose of cocaine (Figure $2 c$ and $d$ ) as well as equal effort expended on a progressive ratio schedule of reinforcement (Figure 2e). Furthermore, general locomotor activity was unchanged and the acute locomotor effects of cocaine $(15 \mathrm{mg} / \mathrm{kg})$ were similar following accumbal GRIP deletion (Figure 2f). Both wild-type and GRIP KO mice extinguished their cocaine-seeking behavior at the same rate, with no differences seen in the responding on the first 3 days of extinction or the time to meet the extinction criterion (Figure $3 \mathrm{a}$ and $\mathrm{b}$ ). Following extinction, mice were exposed to a cue-induced reinstatement session in which active responses resulted in presentation of the cues previously paired with drug administration in the absence of the drug. Although both groups exhibited a significant reinstatement of responding during the cueinduced reinstatement session, we found that mice with accumbal deletion of GRIP exhibited an increase in drug seeking under these conditions compared with wild-type controls (Figure 3c). As mice were trained to self-administer food before cocaine, we also examined cue-induced reinstatement of food seeking. Results demonstrated that the effect of GRIP deletion on cue-induced reinstatement was specific to cocaine and was not influenced by this prior training (Figure 3d). Levels of responding during the food self-administration phase were very high (GFP $=938 \pm 192$; Cre GRIP $\mathrm{KO}=878 \pm 178$ ), and the cue-elicited reinstatement reached levels $\sim 50 \%$ of the self-administration responding. This clearly demonstrates that the lack of increase in our GRIP KO mice was not due to a ceiling effect. This lack of effect on natural reward behavior is consistent with other reports demonstrating cocainespecific effects on AMPAR expression and phosphorylation (Famous et al, 2008), as well as work demonstrating that general manipulations of glutamatergic transmission, or manipulations of CP-AMPARs specifically, do not alter natural reward behaviors (Anderson et al, 2008; Conrad et al, 2008; Famous et al, 2008; Xie et al, 2012). 

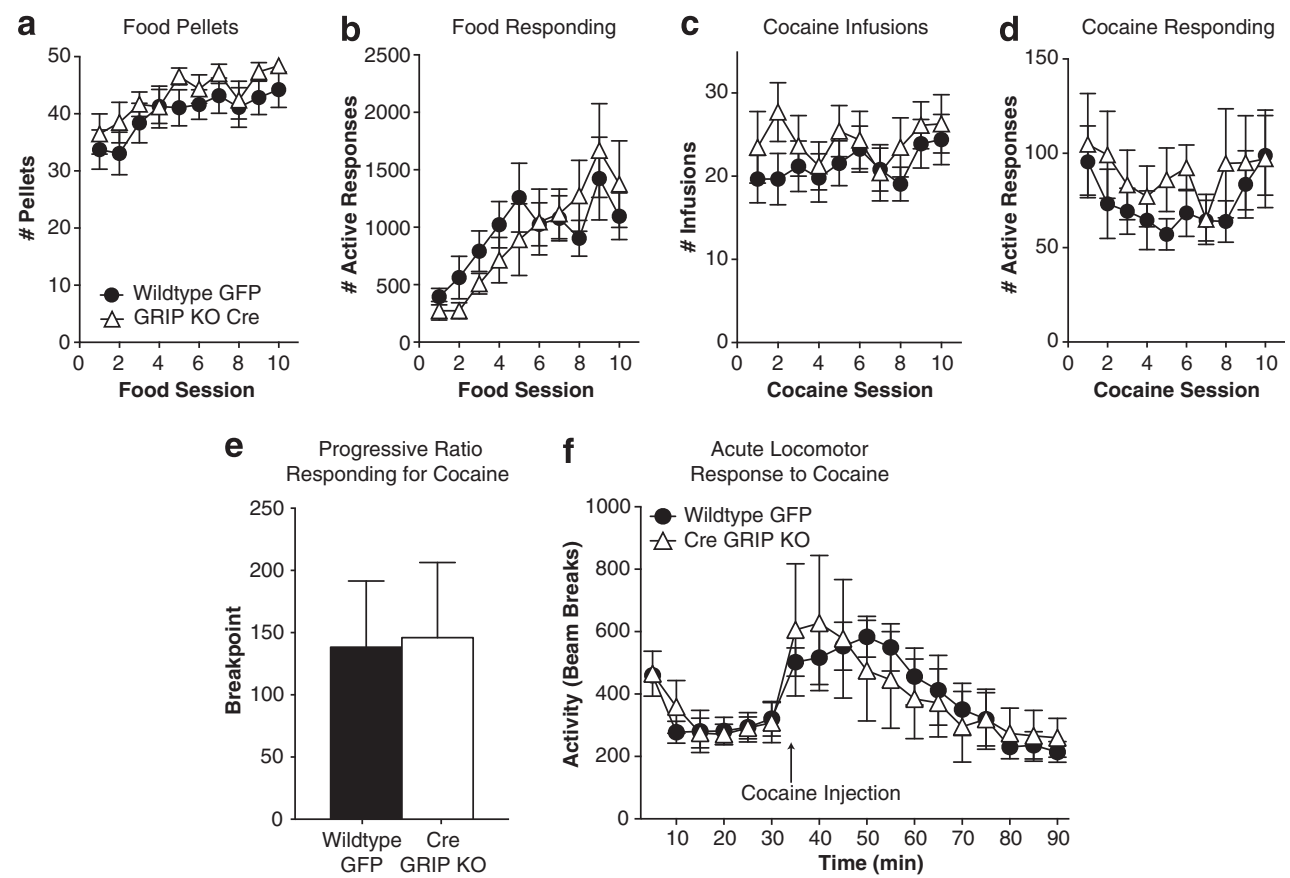

Figure 2 Glutamate receptor-interacting protein (GRIP) deletion in the nucleus accumbens does not alter operant learning, or the reinforcing efficacy or locomotor activating effects of cocaine. Both wild-type $(N=18)$ and GRIP KO $(N=15)$ mice showed a gradual increase in the number of pellets earned (a) and active responses (b) per session over the 10 days of food training (main effect of session, pellets $=F(9,279)=5.33, p<0.000 I ;$ responses $=$ $F(9279)=7.96, p<0.000 \mathrm{I}$ ). No differences were seen between the wild-type and GRIP KO mice in the number of infusions earned (c) or active responses (d) during the 10 days of cocaine self-administration. (e) When cocaine was self-administered under a progressive ratio schedule, no differences were seen between the breakpoints of wild-type $(138.3 \pm 53.2, N=6)$ and GRIP KO mice $(\mid 46.0 \pm 60.4, N=7)$. ( $f$ ) No differences were seen in the locomotor response to a novel environment (time 0-30 min) nor the locomotor response to an acute injection of cocaine (time 35-90 min).
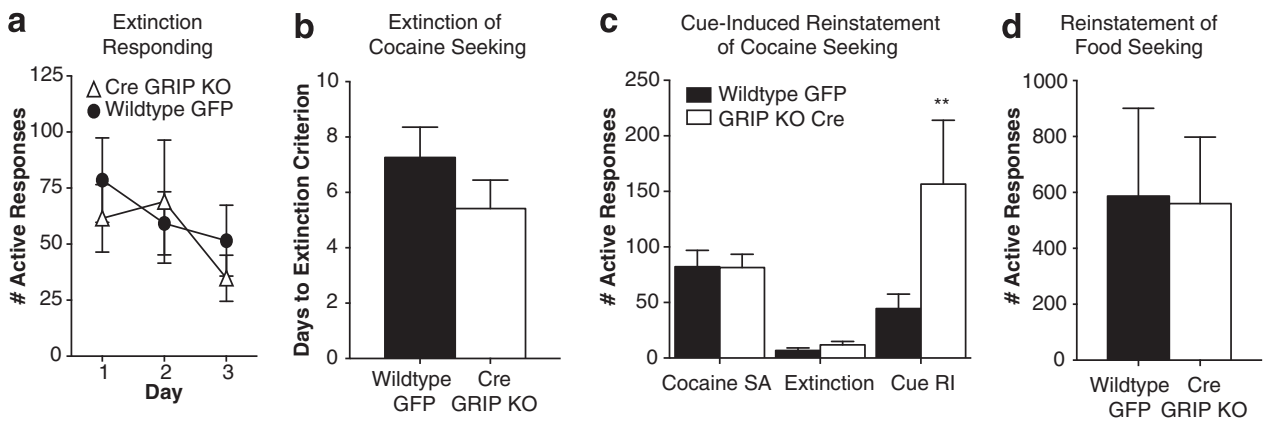

Figure 3 Glutamate receptor-interacting protein (GRIP) deletion in the nucleus accumbens leads to an increase in cue-induced cocaine seeking. No differences were seen between the groups in the responding on the first 3 days of extinction (a) or the number of days of extinction training necessary to meet the criterion (b; wild-type: 7.26 \pm 1.1 ; GRIP KO: $5.41 \pm 1.0 ; \mathrm{t}(29)=1.15, p=0.26$ ). (c) GRIP KO mice exhibit significantly greater responding during cue-induced reinstatement of cocaine seeking (wild-type: $44.50 \pm$ 1 3. I; GRIP KO: $156.50 \pm$ 57.6; interaction between viral injection and test, F(2,56) = 4.99, *** $p=0.00$ I5). (d) No differences were seen between wild-type and GRIP KO mice on cue-induced reinstatement of food seeking (wild-type: $587 \pm 3 \mid 4$, $n=8$; GRIP KO: $560 \pm 237, n=8)$.

\section{Selective Deletion of GRIP in the Nucleus Accumbens Decreases mEPSC Decay Time}

To determine the effect of knockdown of GRIP on AMPARmediated transmission, we measured miniature AMPARmediated EPSCs (mEPSCs) from cells infected with the Cre virus (ie, cells with GRIP KO) and compared them with control cells infected with GFP. In naive animals, we found no effect of GRIP deletion on mEPSC frequency or amplitude (Figure $4 \mathrm{a}-\mathrm{d}$ ), indicating no generalized effects of GRIP deletion on AMPA transmission. However, accumbal GRIP deletion led to a decrease in MEPSC decay time (Figure 4e). The duration of the AMPAR-mediated synaptic currents is determined by the AMPAR subunit composition. Inclusion of the GluA2 subunit, in particular, has been proposed as a determinant of slow synaptic currents (Jonas, 2000; Monyer et al, 1992). Therefore, our results suggest that GRIP KO leads to an increase in GluA2-lacking AMPAR contribution to the synaptic response. Cocaine self-administration and extinction experience led to an increase in mEPSC frequency (Figure $4 \mathrm{~b}$ ) and a decrease in mEPSC amplitude (Figure 4d) relative to cocaine-naive animals in both wild-type and GRIP $\mathrm{KO}$ mice. However, the decrease in mEPSC decay time persisted in the cocaine-experienced GRIP KO mice (Figure 4e). 

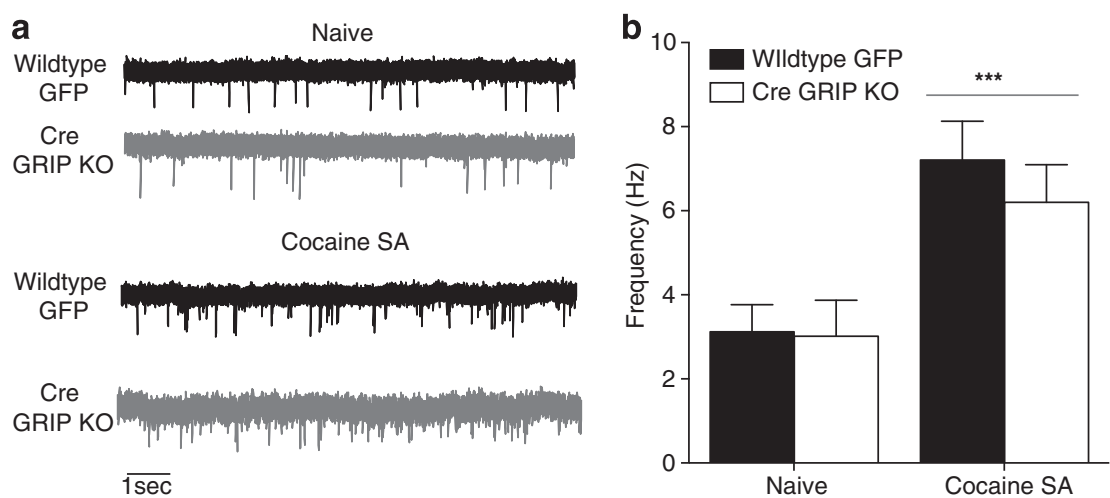

C

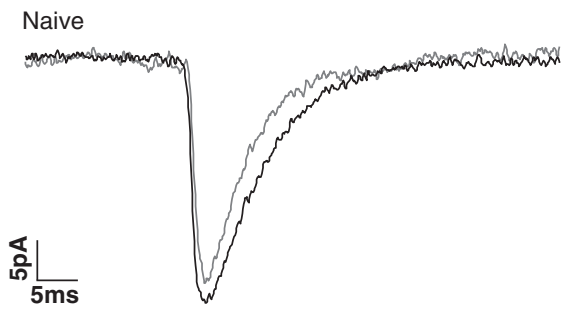

Cocaine SA
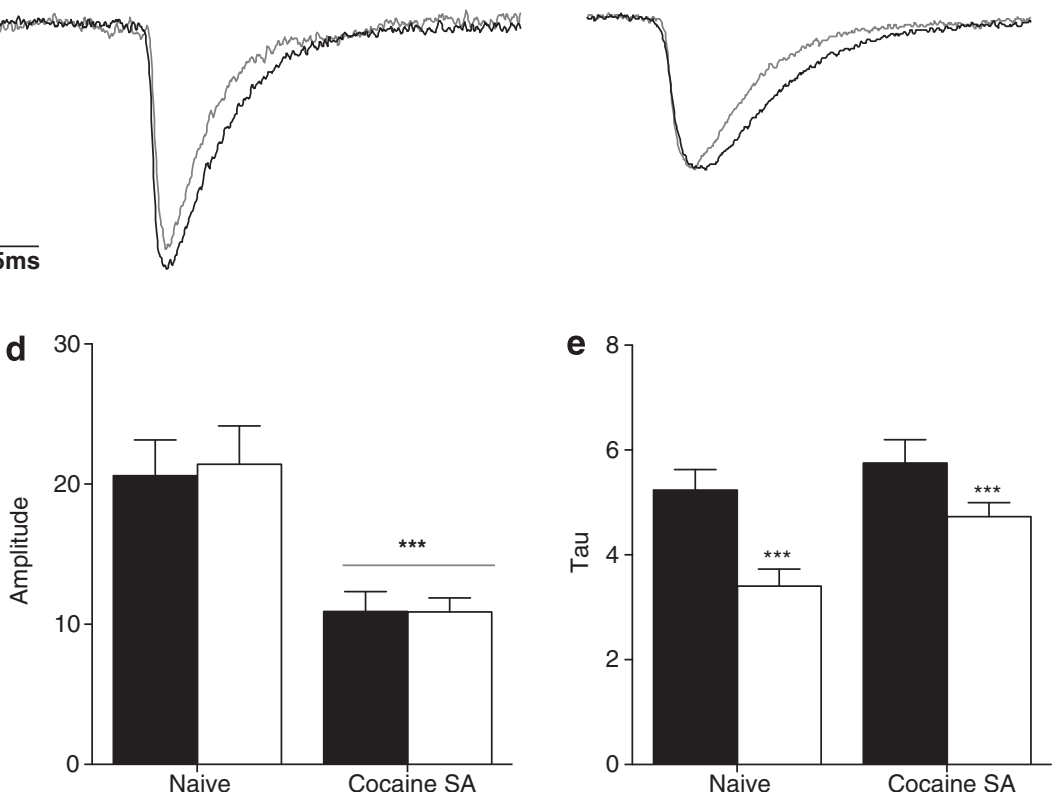

Figure 4 Glutamate receptor-interacting protein (GRIP) knockout decreases AMPA-mediated excitatory postsynaptic current (mEPSC) decay time without affecting frequency or amplitude. (a) Representative traces illustrate effects of GRIP knockout and cocaine experience on mEPSC frequency. (b) Quantification of mEPSC frequency reveals an overall increase in frequency following cocaine self-administration and extinction with no changes due to GRIP deletion (naive WT: $3.12 \pm 0.64, n=15$ cells from three mice; naive GRIP KO: $3.02 \pm 0.86, n=7$ cells from three mice; cocaine SA WT: $7.21 \pm 0.93, n=1$ I cells from three mice; cocaine SA GRIP KO: $6.20 \pm 0.89, n=16$ cells from three mice; main effect of drug experience: $F(I, 44)=15.43, * * * * 2=0.0003)$. (c) Representative traces illustrate effects of GRIP knockout and cocaine experience on mEPSC amplitude and decay time. (d) Quantification of mEPSC amplitude reveals an overall decrease in amplitude following cocaine self-administration and extinction with no changes due to GRIP deletion (naive WT: 20.6 \pm 2.56, $n=16$; naive GRIP KO: $21.4 \pm 2.74, n=9$; cocaine SA WT: I0.9 \pm I.4I, $n=14$; cocaine SA GRIP KO: I0.9 \pm 1.01 , $n=17$; main effect of drug experience: $F(I, 52)=25.5$, **** $p<0.000 \mathrm{I}$ ). (e) Quantification of mEPSC decay time (tau) reveals a decrease in decay time following GRIP deletion regardless of cocaine history (naive WT: $5.24 \pm 0.39, n=17$; naive GRIP KO: $3.41 \pm 0.32, n=8$; cocaine SA WT: $5.75 \pm 0.44, n=1$ I; cocaine SA GRIP KO: $4.73 \pm 0.27, n=16$; main effect of viral injection: $F(1,50)=13.26$, $* * * p=0.0006$ ).

\section{Selective Deletion of GRIP in the Nucleus Accumbens Increases the Contribution of GluA2-Lacking AMPA Receptors}

Currents mediated by GluA2-lacking AMPARs have a characteristic inward rectification mediated by a voltagedependent polyamine block of the channel pore. To verify that GRIP KO had an effect on the expression of GluA2lacking AMPARs, we characterized stimulus-evoked EPSCs in the nucleus accumbens of naive and cocaine-experienced mice following accumbal GRIP deletion. We found that GRIP deletion led to an increase in the rectification of EPSCs in both naive and cocaine-experienced mice (rectification index $=$ slope of a linear fit of $\mathrm{I}-\mathrm{V}$ points between -70 and $0 \mathrm{mV}$ over the slope of a linear fit of $\mathrm{I}-\mathrm{V}$ points between 0 and $+40 \mathrm{mV}$; Figure $5 \mathrm{a}-\mathrm{c}$ ). Further, in slices from cocaineexperienced animals, we measured the evoked EPSCs following bath application of the CP-AMPAR antagonist, 1-naphthylacetyl spermine (Naspm) in GRIP-deleted accumbal cells. We found that Naspm led to a greater decrease in evoked response following GRIP deletion compared with GFP control cells (Figure 5d). These results combined with our mEPSC data indicate that GRIP deletion leads to an increased contribution of CP-AMPARs without dramatically altering the overall strength of AMPAR-mediated synaptic signaling at glutamatergic synapses in the nucleus accumbens. 
a
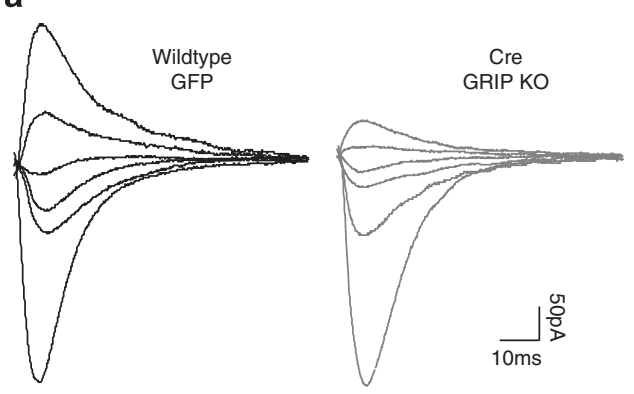

b
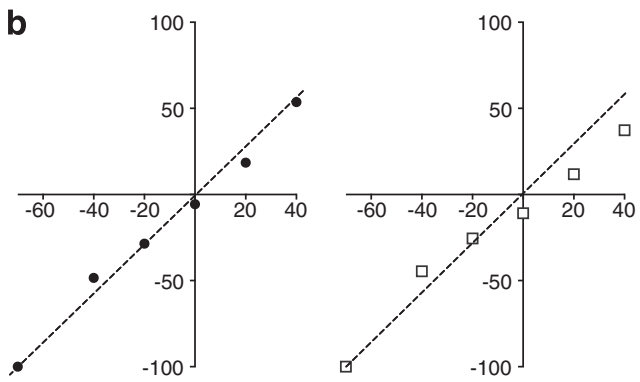
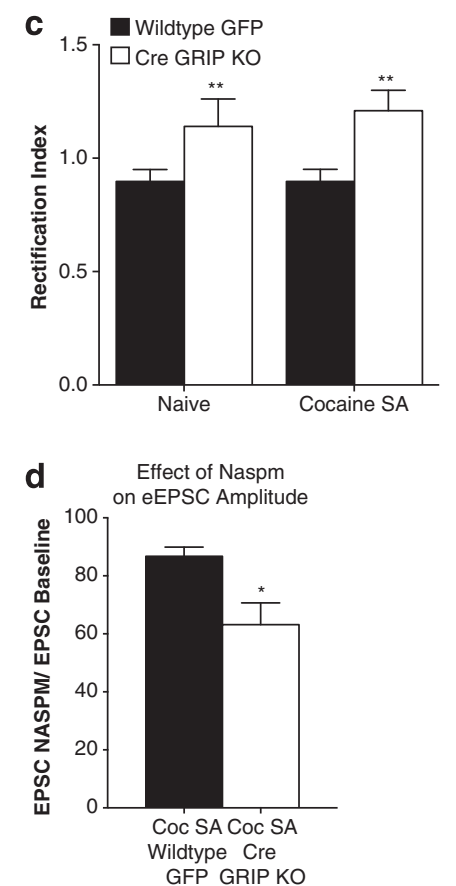

Figure 5 Glutamate receptor-interacting protein (GRIP) knockout leads to an increase in rectification associated with an increase in calcium-permeable AMPARs (CP-AMPARs). (a) Representative traces of AMPAR-mediated excitatory postsynaptic currents (EPSCs) recorded at $+40,+20,0,-20,-40$ and $-70 \mathrm{mV}$ in neurons from cocaine-experienced wild-type and GRIP KO mice. (b) I-V plots of normalized and averaged AMPAR EPSCs of wild-type (black circles) and GRIP KO (gray squares) mice. (c) Quantification of rectification index reveals an increase in rectification following GRIP deletion regardless of cocaine history (naive WT: $0.90 \pm 0.05, n=10$; naive GRIP KO: $1.14 \pm 0.12, n=14$; cocaine SA WT: 0.90 $\pm 0.05, n=12$; cocaine SA GRIP KO: $1.21 \pm 0.09, n=21$; main effect of viral injection: $F(I, 53)=7.97$, $* * 0=0.0067)$. (d) As indicated by the EPSC Naspm/EPSC baseline ratio, Naspm sensitivity in cells from cocaine-experienced GRIP KO mice was higher than in cells from cocaine-experienced wild-type mice (cocaine SA WT: 86.75 $\pm 3.16, n=6$; cocaine SA GRIP KO: $63.20 \pm 7.48, n=6 ; t(10)=2.31$, * $p=0.02)$.

\section{GRIP is Necessary for Long-Term Depression in the Nucleus Accumbens}

As GRIP has been demonstrated to have a role in cerebellar LTD (Takamiya et al, 2008), we wanted to examine how GRIP deletion would affect long-term depression in the nucleus accumbens. As blunted accumbal LTD is seen following cocaine experience, we hypothesized that LTD would be reduced in GRIP KO mice. We found that lowfrequency train of stimuli $(1 \mathrm{~Hz}, 7.5 \mathrm{~min})$ induced robust LTD in accumbal slices from wild-type control mice, but did not elicit LTD in GRIP knockout mice (Figure 6a and b). Neither wild-type nor GRIP knockout mice exhibited LTD following cocaine self-administration and extinction (Figure $6 \mathrm{c}$ and $\mathrm{d}$ ).

\section{DISCUSSION}

Here, we present evidence that the AMPAR-anchoring protein, GRIP, has a critical role in mediating vulnerability to cue-induced cocaine relapse. Our data demonstrate that deletion of accumbal GRIP increases vulnerability to cueinduced cocaine relapse without altering the reinforcing properties of the drug or the response to natural rewards. This increase in cocaine vulnerability is associated with AMPAR-mediated synaptic changes. We demonstrate that GRIP deletion leads to an increase in GluA2-lacking CPAMPAR transmission similar to what is seen following extended access/prolonged withdrawal models of cocaine self-administration (Conrad et al, 2008; McCutcheon et al, 2011b). In addition, GRIP knockdown interferes with the induction of LTD at accumbal synapses highlighting a local circuit deficit that is also present following abstinence following cocaine exposure (Kasanetz et al, 2010; Martin et al, 2006; Moussawi et al, 2009).

\section{GRIP Knockdown in the Nucleus Accumbens Potentiates Cue-Induced Reinstatement of Cocaine Seeking}

Cocaine relapse is in part mediated by the enduring changes in the salience of previously neutral stimuli that are associated with drug use (Robinson and Berridge, 2008). The presentation of cocaine-paired cues elicits drug craving in addicts and the level of this craving can directly predict relapse rates (Back et al, 2010; O'Brien et al, 1998). The present data indicate that knocking down GRIP in the nucleus accumbens increases cue-induced reinstatement of cocaine seeking. These findings are the first to implicate GRIP function in cocaine seeking and one of the few studies directly linking this trafficking protein to behavior.

Previous work demonstrated that phosphorylation of GluA2 subunits at serine 880 by protein kinase $C$ leads to a dissociation between GRIP and GluA2 (Matsuda et al, 1999; Pierce and Wolf, 2013). Decreased GluA2 phosphorylation is seen following extinction of cocaine-seeking and cocaineprimed reinstatement causes a subsequent increase in phosphorylation (Famous et al, 2008), suggesting that 

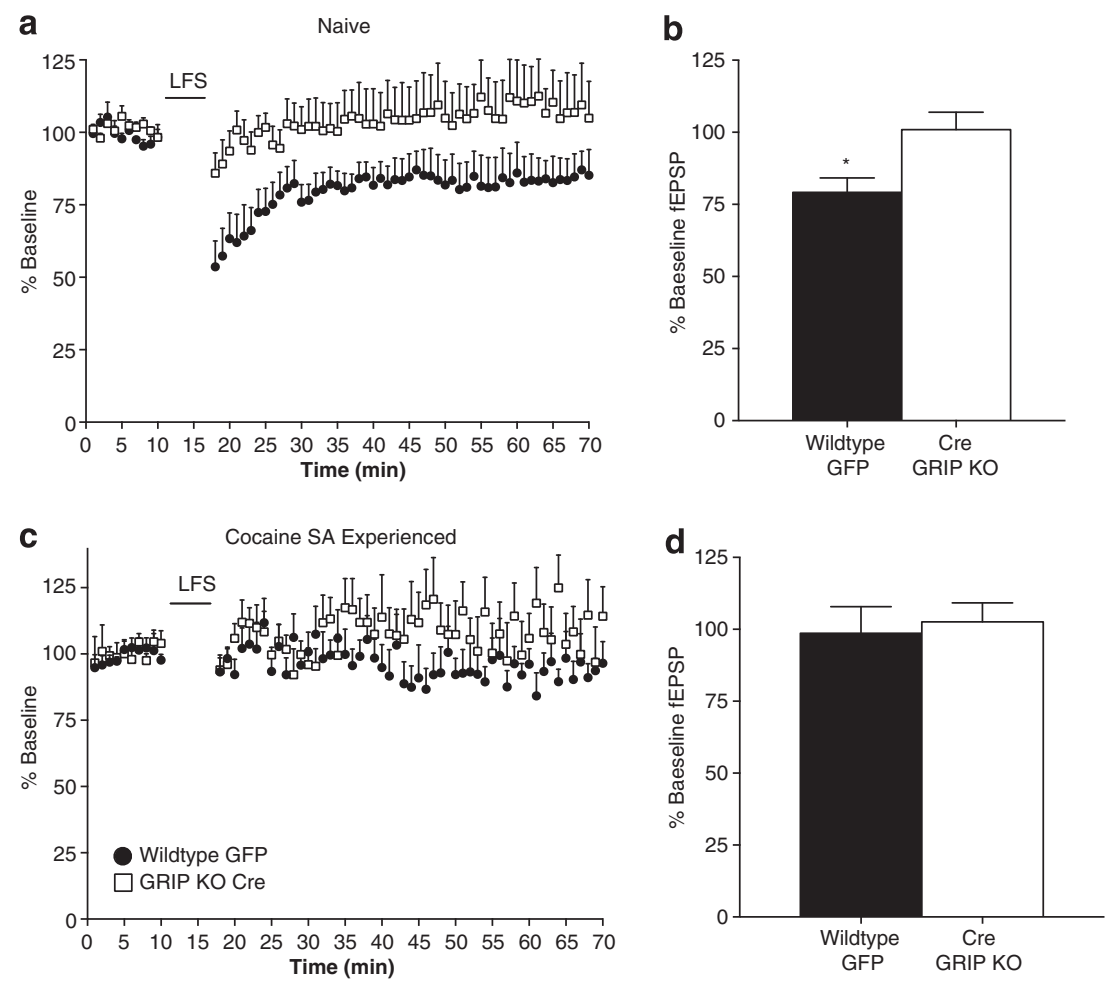

Figure 6 Accumbal LTD is abolished in slices from naive glutamate receptor-interacting protein (GRIP) KO mice, mimicking what is seen following withdrawal from cocaine. (a) LTD induction by low-frequency stimulation (LFS = I Hz for $7.5 \mathrm{~min}$ ) in slices from naive wild-type and GRIP KO mice. (b) Change in fEPSP amplitude across the 30-min post LFS demonstrates a robust LTD in wild-type mice, which is blocked in GRIP KO mice (wild-type: $79.2 \pm 5.0 \%, n=8 ;$ GRIP KO: $101 \pm 6.0 \%, n=8$; $\mathrm{t}(\mid 4)=2.78$, * $p=0.015)$. (c) LFS does not induce LTD in slices from cocaine withdrawn wild-type or GRIP $\mathrm{KO}$ mice. (d) Change in fEPSP amplitude across the 30-min post LFS demonstrates that cocaine self-administration and extinction blocks LTD in wild-type mice (wild-type: $98.7 \pm 9.2 \%, n=6$; GRIP KO: $103 \pm 6.6 \%, n=7$ ).

cocaine experience can dynamically alter the interaction between GluA2 and GRIP. Furthermore, prenatal cocaine experience increases phosphorylation of GRIP, leading to a decrease in the GluA2/GRIP interaction (Bakshi et al, 2009a). As mice exposed to prenatal cocaine exhibit an increase in the vulnerability to addiction (Malanga et al, 2008), this previous work, taken together with the present findings, suggests that persistent cocaine-induced changes in GRIP function could influence cocaine-mediated behaviors. To date, there is no evidence that GRIP expression is altered by cocaine experience, but further work is needed to determine whether cocaine could lead to alterations in GRIP function. As functional single-nucleotide polymorphisms within the GRIP1 gene have been identified and associated with behavioral differences (Mejias et al, 2011), it would be interesting to determine whether GRIP variants could alter relapse vulnerability.

Active extinction training may lead to alterations in glutamatergic transmission that are similar to those observed following GRIP deletion. For example, GRIP deletion increased the contribution of GluA1-containing AMPA receptors, and increased GluA1 expression is seen following extinction training (Ghasemzadeh et al, 2009). As viral overexpression of GluA1 in the accumbens shell facilitates extinction learning (Sutton et al, 2003), these findings might lead one to expect that extinction learning would also be enhanced following GRIP deletion. However, we did not see any effect of GRIP deletion on extinction behavior. General overexpression of GluA1 is likely to increase availability of both CP-AMPARs (GluA2-lacking) and CI-AMPARs (GluA2-containing), whereas GRIP deletion, as reported in the current study, preferentially increases CP-AMPAR-mediated neurotransmission only. Furthermore, increased expression of GluA1 following extinction as well the viral overexpression of GluA1 leading to enhanced extinction learning are reported in the nucleus accumbens shell (Ghasemzadeh et al, 2009; Sutton et al, 2003), whereas our study did not draw a distinction between accumbal subregions. Given these differences, it is difficult to pinpoint the exact reasons for normal extinction learning in our mice.

\section{Blocking Activity-Dependent Trafficking of GluA2- Containing AMPARs Leads to an Enhancement of CP- AMPAR-Mediated Neurotransmission}

As GRIP associates specifically with GluA2/3 subunits and does not interact directly with GluA1 subunits (Dong et al, 1997), deletion of GRIP should specifically affect the anchoring of GluA2-containing AMPARs and decrease their synaptic expression. However, in the current study, we did not see a change in AMPAR-mediated mEPSC amplitude following GRIP deletion. We argue that this is due to a compensatory increase in AMPARs that do not interact with GRIP. Indeed, a decrease in mEPSC decay time following GRIP deletion is consistent with faster decay kinetics of GluA2-lacking AMPARs (Jonas, 2000; Mosbacher et al, 1994). Our findings of increased AMPAR-mediated inward 
rectification and increased AMPAR sensitivity to Naspm further demonstrate that GRIP deletion leads to an increased contribution of GluA2-lacking CP-AMPARs at synapses onto the medium spiny neurons of the NAc.

Although others have demonstrated a clear role for $\mathrm{CP}$ AMPARs in extended access models of cocaine relapse (Conrad et al, 2008; McCutcheon et al, 2011b), alterations in surface expression of CP-AMPARs do not occur following shorter access self-administration paradigms, similar to the protocol used in the current paper (McCutcheon et al, 2011b). Furthermore, these increases in CP-AMPAR are seen only following prolonged withdrawal periods that are longer than the current extinction period (Mameli et al, 2009; McCutcheon et al, 2011b). Consistent with this, we do not see increases in CP-AMPAR transmission in our wildtype animals following the 2-week self-administration procedure and extinction. However, GRIP deletion leads to an increase in CP-AMPAR transmission in the absence of extended access cocaine or extended withdrawal, suggesting that accelerating CP-AMPAR trafficking to accumbens synapses may enhance cocaine seeking. This leads to an intriguing speculation that, in the absence of available CPAMPAR agonists, deletion of GRIP might be used as a proxy for such an agent.

Although the effects of GRIP deletion are independent of cocaine experience, it is important to note that we saw no baseline behavioral differences as indicated by the lack of alterations in the locomotor response to novelty or operant learning. Therefore, the alterations in LTD depression and CP-AMPARs only manifest themselves behaviorally when animals are exposed to a cue-induced reinstatement session. Consistent with findings in the literature, we found that cocaine experience leads to an increase in mEPSC frequency (Kourrich et al, 2007) and a decrease in mEPSC amplitude (Ortinski et al, 2012). These cocaine-induced alterations are likely to interact with those induced by GRIP deletion and this may be why baseline behavioral deficits are not seen. Further work will need to be done to examine how these alterations may interact.

In contrast to our finding that cocaine self-administration and extinction leads to a decrease in mEPSC amplitude, others have reported increases in spontaneous EPSC (sEPSC) amplitude following similar behavioral paradigms (Ma et al, 2013; Trantham-Davidson et al, 2012). Notably, in $\mathrm{Ma}$ et al (2013) the increase was isolated to the nucleus accumbens core with decreased sEPSC amplitudes reported in the shell of the nucleus accumbens. Furthermore, and aside from methodological differences between studies (eg, choice of species and duration of extinction training), we observe changes in the action-potential-independent mEPSC, in contrast to the previous reports that focused on action-potential-dependent sEPSCs. This distinction is not trivial, especially given that $\mathrm{Ma}$ et al (2013) note that it is only the sEPSC, and not the mEPSC, amplitude that is sensitive to modulation by exogenously applied cocaine.

\section{GRIP Function in the Nucleus Accumbens is Necessary for Long-Term Depression}

The ability of glutamatergic synapses to undergo neuroplasticity is critical for learning new information and updating information about the changing value of stimuli in the environment. In particular, LTD in the nucleus accumbens is considered important in depotentiating synapses that have been enhanced during the acquisition of skill learning or conditioned cue associations (Kasanetz et al, 2010; Yin et al, 2009). Without this ability to rescale these synapses, future learning could be occluded (Braunewell and Manahan-Vaughan, 2001; Ito, 1986). We report that the presence of GRIP in the nucleus accumbens is necessary for the expression of LTD and that its knockdown leads to blunted LTD seen also after cocaine self-administration/extinction. It is interesting that in vivo LTD is only blunted following active extinction training (Knackstedt et al, 2010), whereas multiple studies have demonstrated blunted in vitro LTD following cocaine selfadministration and abstinence (Kasanetz et al, 2010; Martin et al, 2006). The current study complements the in vitro LTD findings to demonstrate that extinction of cocaine selfadministration responding does not influence the ability of cocaine experience to impair LTD.

Consistent with what has been seen in other brain regions (Dickinson et al, 2009; Takamiya et al, 2008), blunted LTD following GRIP deletion supports the involvement of the trafficking of GluA2-containing AMPARs in accumbal LTD. Although there was an incomplete knockout of GRIP protein, LTD was blocked completely. Given that the protein pools sampled by the western blot and the physiology differ (ie, neuronal and glial GRIP in western blot; synaptic AMPA receptors in physiology), this result is not surprising. Although plasticity in CP-AMPARs has been reported to require prolonged drug taking and withdrawal (McCutcheon et al, 2011b), impaired LTD occurs in the nucleus accumbens following a short access cocaine self-administration (Bellone and Luscher, 2006; Kasanetz et al, 2010; Martin et al, 2006; Moussawi et al, 2009). Furthermore, the extent to which LTD is permanently blunted following cocaine self-administration has been linked to addictive phenotypes, and manipulations that restore LTD expression also lead to a decrease in reinstatement of cocaine seeking (Kasanetz et al, 2010; Moussawi et al, 2009). The current study provides further evidence that blunted LTD expression may enhance cocaine seeking and provides a potential mechanism for altering this form of plasticity.

\section{CONCLUSIONS}

The current results indicate that GRIP knockdown in the nucleus accumbens leads to a highly specific increase in vulnerability to cue-induced cocaine seeking. Furthermore, GRIP knockdown in the accumbens leads to an increase in CP-AMPAR transmission and blunted LTD, two independent forms of plasticity linked to addiction. Accordingly, the current study demonstrates a clear role for the interaction between accumbal GRIP and GluA2 in behavioral and synaptic plasticity. This report is the first to demonstrate a role for GRIP in cocaine relapse and accumbal synaptic strengthening associated with cocaine taking. These results suggest that pharmacotherapies augmenting the interaction between GRIP and GluA2 may be effective in the treatment of cocaine craving and addiction. 


\section{FUNDING AND DISCLOSURE}

The authors declare no conflict of interest.

\section{ACKNOWLEDGEMENTS}

This work was supported by National Institute on Drug Abuse (NIDA) Grant K99 DA033372 (LAB), K01 DA031747 (PIO), R01 DA015214 (RCP.), R01 DA022339 (RCP), and K02 DA018678 (RCP).

\section{REFERENCES}

Alleweireldt AT, Weber SM, Neisewander JL (2001). Passive exposure to a contextual discriminative stimulus reinstates cocaineseeking behavior in rats. Pharmacol, Biochem Behav 69: 555-560. Anderson SM, Famous KR, Sadri-Vakili G, Kumaresan V, Schmidt HD, Bass CE et al (2008). CaMKII: a biochemical bridge linking accumbens dopamine and glutamate systems in cocaine seeking. Nat Neurosci 11: 344-353.

Back SE, Hartwell K, DeSantis SM, Saladin M, McRae-Clark AL, Price KL et al (2010). Reactivity to laboratory stress provocation predicts relapse to cocaine. Drug Alcohol Depend 106: 21-27.

Bakshi K, Gennaro S, Chan CY, Kosciuk M, Liu J, Stucky A et al (2009a). Prenatal cocaine reduces AMPA receptor synaptic expression through hyperphosphorylation of the synaptic anchoring protein GRIP. J Neurosci 29: 6308-6319.

Bakshi K, Gennaro S, Chan CY, Kosciuk M, Liu J, Stucky A et al (2009b). Prenatal cocaine reduces AMPA receptor synaptic expression through hyperphosphorylation of the synaptic anchoring protein GRIP. J Neurosci 29: 6308-6319.

Bellone C, Luscher C (2006). Cocaine triggered AMPA receptor redistribution is reversed in vivo by mGluR-dependent longterm depression. Nat Neurosci 9: 636-641.

Boudreau AC, Reimers JM, Milovanovic M, Wolf ME (2007). Cell surface AMPA receptors in the rat nucleus accumbens increase during cocaine withdrawal but internalize after cocaine challenge in association with altered activation of mitogen-activated protein kinases. J Neurosci 27: 10621-10635.

Braunewell KH, Manahan-Vaughan D (2001). Long-term depression: a cellular basis for learning? Rev Neurosci 12: 121-140.

Ciccocioppo R, Sanna PP, Weiss F (2001). Cocaine-predictive stimulus induces drug-seeking behavior and neural activation in limbic brain regions after multiple months of abstinence: reversal by D(1) antagonists. Proc Natl Acad Sci USA 98: 1976-1981.

Clements JD, Bekkers JM (1997). Detection of spontaneous synaptic events with an optimally scaled template. Biophys $J$ 73: $220-229$.

Conrad KL, Tseng KY, Uejima JL, Reimers JM, Heng LJ, Shaham Y et al (2008). Formation of accumbens GluR2-lacking AMPA receptors mediates incubation of cocaine craving. Nature 454: 118-121.

Dickinson BA, Jo J, Seok H, Son GH, Whitcomb DJ, Davies CH et al (2009). A novel mechanism of hippocampal LTD involving muscarinic receptor-triggered interactions between AMPARs, GRIP and liprin-alpha. Mol Brain 2: 18.

Dong H, O'Brien RJ, Fung ET, Lanahan AA, Worley PF, Huganir RL (1997). GRIP: a synaptic PDZ domain-containing protein that interacts with AMPA receptors. Nature 386: 279-284.

Famous KR, Kumaresan V, Sadri-Vakili G, Schmidt HD, Mierke DF, Cha JH et al (2008). Phosphorylation-dependent trafficking of GluR2-containing AMPA receptors in the nucleus accumbens plays a critical role in the reinstatement of cocaine seeking. J Neurosci 28: 11061-11070.

Ghasemzadeh MB, Vasudevan P, Mueller C, Seubert C, Mantsch JR (2009). Region specific alterations in glutamate receptor expression and subcellular distribution following extinction of cocaine self-administration. Brain Res 1267: 89-102.

Hyman SE, Malenka RC, Nestler EJ (2006). Neural mechanisms of addiction: the role of reward-related learning and memory. Annu Rev Neurosci 29: 565-598.

Ito M (1986). Long-term depression as a memory process in the cerebellum. Neurosci Res 3: 531-539.

Jonas P (2000). The time course of signaling at central glutamatergic synapses. News Physiol Sci 15: 83-89.

Kasanetz F, Deroche-Gamonet V, Berson N, Balado E, Lafourcade $\mathrm{M}$, Manzoni $\mathrm{O}$ et al (2010). Transition to addiction is associated with a persistent impairment in synaptic plasticity. Science 328: 1709-1712.

Knackstedt LA, Moussawi K, Lalumiere R, Schwendt M, Klugmann M, Kalivas PW (2010). Extinction training after cocaine selfadministration induces glutamatergic plasticity to inhibit cocaine seeking. J Neurosci 30: 7984-7992.

Kourrich S, Rothwell PE, Klug JR, Thomas MJ (2007). Cocaine experience controls bidirectional synaptic plasticity in the nucleus accumbens. J Neurosci 27: 7921-7928.

Lu L, Grimm JW, Shaham Y, Hope BT (2003). Molecular neuroadaptations in the accumbens and ventral tegmental area during the first 90 days of forced abstinence from cocaine selfadministration in rats. J Neurochem 85: 1604-1613.

Ma YY, Henley SM, Toll J, Jentsch D, Evans CJ, Levine MS et al (2013). Drug-primed reinstatement of cocaine seeking in mice: increased excitability of medium-sized spiny neurons in the nucleus accumbens. ASN Neuro (e-pub ahead of print).

Malanga CJ, Riday TT, Carlezon WA Jr., Kosofsky BE (2008). Prenatal exposure to cocaine increases the rewarding potency of cocaine and selective dopaminergic agonists in adult mice. Biol Psychiatry 63: 214-221.

Mameli M, Halbout B, Creton C, Engblom D, Parkitna JR, Spanagel $\mathrm{R}$ et al (2009). Cocaine-evoked synaptic plasticity: persistence in the VTA triggers adaptations in the NAc. Nat Neurosci 12: 1036-1041.

Martin M, Chen BT, Hopf FW, Bowers MS, Bonci A (2006). Cocaine self-administration selectively abolishes LTD in the core of the nucleus accumbens. Nat Neurosci 9: 868-869.

Matsuda S, Mikawa S, Hirai H (1999). Phosphorylation of serine- 880 in GluR2 by protein kinase $C$ prevents its $C$ terminus from binding with glutamate receptor-interacting protein. J Neurochem 73: 1765-1768.

McCutcheon JE, Loweth JA, Ford KA, Marinelli M, Wolf ME, Tseng KY (2011a). Group I mGluR activation reverses cocaineinduced accumulation of calcium-permeable AMPA receptors in nucleus accumbens synapses via a protein kinase C-dependent mechanism. J Neurosci 31: 14536-14541.

McCutcheon JE, Wang X, Tseng KY, Wolf ME, Marinelli M (2011b). Calcium-permeable AMPA receptors are present in nucleus accumbens synapses after prolonged withdrawal from cocaine self-administration but not experimenter-administered cocaine. J Neurosci 31: 5737-5743.

McFall ME, Mackay PW, Donovan DM (1992). Combat-related posttraumatic stress disorder and severity of substance abuse in Vietnam veterans. J Stud Alcohol 53: 357-363.

Mejias R, Adamczyk A, Anggono V, Niranjan T, Thomas GM, Sharma K et al (2011). Gain-of-function glutamate receptor interacting protein 1 variants alter GluA2 recycling and surface distribution in patients with autism. Proc Natl Acad Sci USA 108: $4920-4925$.

Monyer H, Sprengel R, Schoepfer R, Herb A, Higuchi M, Lomeli H et al (1992). Heteromeric NMDA receptors: molecular and functional distinction of subtypes. Science 256: 1217-1221.

Mosbacher J, Schoepfer R, Monyer H, Burnashev N, Seeburg PH, Ruppersberg JP (1994). A molecular determinant for submillisecond desensitization in glutamate receptors. Science 266: 1059-1062. 
Moussawi K, Pacchioni A, Moran M, Olive MF, Gass JT, Lavin A et al (2009). N-Acetylcysteine reverses cocaine-induced metaplasticity. Nat Neurosci 12: 182-189.

O’Brien CP, Childress AR, Ehrman R, Robbins SJ (1998). Conditioning factors in drug abuse: can they explain compulsion? J Psychopharmacol 12: 15-22.

Ortinski PI, Turner JR, Pierce RC (2013). Extrasynaptic targeting of NMDA receptors following D1 dopamine receptor activation and cocaine self-administration. J Neurosci 33: 9451-9461.

Ortinski PI, Vassoler FM, Carlson GC, Pierce RC (2012). Temporally dependent changes in cocaine-induced synaptic plasticity in the nucleus accumbens shell are reversed by D1-like dopamine receptor stimulation. Neuropsychopharmacology 37: 1671-1682.

Ouimette P, Coolhart D, Funderburk JS, Wade M, Brown PJ (2007). Precipitants of first substance use in recently abstinent substance use disorder patients with PTSD. Addict Behav 32: 1719-1727.

Pierce RC, Wolf ME (2013). Psychostimulant-induced neuroadaptations in nucleus accumbens AMPA receptor transmission. Cold Spring Harb Perspect Med 3: a012021.

Purgianto A, Scheyer AF, Loweth JA, Ford KA, Tseng KY, Wolf ME (2013). Different Adaptations in AMPA Receptor Transmission in the Nucleus Accumbens after Short vs Long Access Cocaine Self-Administration Regimens. Neuropsychopharmacology 38: 1789-1797.

Reimers JM, Milovanovic M, Wolf ME (2011). Quantitative analysis of AMPA receptor subunit composition in addiction-related brain regions. Brain Res 1367: 223-233.

Robinson TE, Berridge KC (2008). Review. The incentive sensitization theory of addiction: some current issues. Philos Trans $R$ Soc Lond B Biol Sci 363: 3137-3146.

Summa M, Di Prisco S, Grilli M, Marchi M, Pittaluga A (2011). Hippocampal AMPA autoreceptors positively coupled to NMDA autoreceptors traffic in a constitutive manner and undergo adaptative changes following enriched environment training. Neuropharmacology 61: 1282-1290.

Sutton MA, Schmidt EF, Choi KH, Schad CA, Whisler K, Simmons $\mathrm{D}$ et al (2003). Extinction-induced upregulation in AMPA receptors reduces cocaine-seeking behaviour. Nature 421: 70-75.

Takamiya K, Mao L, Huganir RL, Linden DJ (2008). The glutamate receptor-interacting protein family of GluR2-binding proteins is required for long-term synaptic depression expression in cerebellar Purkinje cells. J Neurosci 28: 5752-5755.

Tang W, Wesley M, Freeman WM, Liang B, Hemby SE (2004). Alterations in ionotropic glutamate receptor subunits during binge cocaine self-administration and withdrawal in rats. J Neurochem 89: 1021-1033.

Trantham-Davidson H, LaLumiere RT, Reissner KJ, Kalivas PW, Knackstedt LA (2012). Ceftriaxone normalizes nucleus accumbens synaptic transmission, glutamate transport, and export following cocaine self-administration and extinction training. J Neurosci 32: 12406-12410.

Volkow ND, Wang GJ, Telang F, Fowler JS, Logan J, Childress AR et al (2006). Cocaine cues and dopamine in dorsal striatum: mechanism of craving in cocaine addiction. J Neurosci 26: 6583-6588.

Wolf ME (2002). Addiction: making the connection between behavioral changes and neuronal plasticity in specific pathways. Mol Interv 2: 146-157.

Xie X, Lasseter HC, Ramirez DR, Ponds KL, Wells AM, Fuchs RA (2012). Subregion-specific role of glutamate receptors in the nucleus accumbens on drug context-induced reinstatement of cocaine-seeking behavior in rats. Addict Biol 17: 287-299.

Xue L, Zhang F, Chen X, Lin J, Shi J (2010). PDZ protein mediated activity-dependent LTP/LTD developmental switch at rat retinocollicular synapses. Am J Physiol Cell Physiol 298: C1572-C1582.

Yin HH, Mulcare SP, Hilario MR, Clouse E, Holloway T, Davis MI et al (2009). Dynamic reorganization of striatal circuits during the acquisition and consolidation of a skill. Nature Neurosci 12: 333-341. 